\title{
Primary leiomyosarcoma of the oral cavity: A case report and review of the literature
}

\author{
A Fasanmade BDS FDS RCS ${ }^{1}$, AW Barrett PhD FDS RCS(Ed) MRCPath ${ }^{2}$, \\ L Newman FDS RCS FFD RCSI FRCS ${ }^{3}$, NC Hyde FDS RCS FRCS 3
}

A Fasanmade, AW Barrett, L Newman, NC Hyde. Primary leiomyosarcoma of the oral cavity: A case report and review of the literature. Can J Plast Surg 2002;10(3):113-116.

Leiomyosarcoma is a malignant tumour of mesenchymal origin that is uncommon in the head and neck, and particularly uncommon in the oral cavity. This article presents a case of primary leiomyosarcoma affecting the mucosal lining of the cheek in a 35year-old woman. The need for wide excision is emphasized, and because of the high frequency of regional lymph node metastasis, an ipsilateral neck dissection is advocated, followed by adjuvant radiotherapy for residual microscopic disease.

Key Words: Leiomyosarcoma; Oral cavity

\section{Le léiomyosarcome primaire de la cavité buccale : Un rapport de cas et une analyse bibliographique}

RÉSUMÉ : Le léiomyosarcome est une tumeur maligne d'origine mésenchimateuse qui est rare sur la tête et le cou, et encore plus dans la cavité buccale. Le présent article présente un cas de léiomyosarcome primaire qui touche la muqueuse de la joue chez une femme de 35 ans. Le besoin d'effectuer une large excision est souligné et, en raison de la fréquence élevée de métastases régionales des ganglions lymphatiques, une dissection homolatérale du cou est préconisée, suivie par une radiothérapie adjuvante visant à éradiquer la maladie microscopique résiduelle.
L eiomyosarcoma is a malignant tumour presumed to be of smooth muscle origin that most often occurs in the uterus and gastrointestinal tract. Leiomyosarcoma at other sites appears to be biologically different and has been divided into three main groups (1): retroperitoneal or intraabdominal, cutaneous or subcutaneous and, least common, those that arise from medium- to large-sized veins. Leiomyosarcoma is a rare neoplasm in the head and neck, and is particularly rare in the oral cavity, with only 71 previously reported cases of primary oral leiomyosarcoma (2-12). Of these, only nine occurred in the cheek (13). The present article reports a case of primary intraoral leiomyosarcoma arising beneath the mucosa of the left cheek with infiltration of the mandible. The management of this tumour is discussed and the literature is reviewed.

\section{CASE PRESENTATION}

A 35-year-old white, female food scientist presented with a swelling $(2.5 \mathrm{~cm}$ in diameter), deep to the mucosa of her left posterior cheek that had been present for four to six weeks. The lesion was adjacent to a partially erupted lower left third molar, and the overlying mucosa was intact, though slightly erythematous (Figure 1). The rest of the oral cavity was otherwise healthy and there was no cervical lymphadenopathy. The mass had grown progressively but was otherwise asymptomatic, aside from mild intermittent discomfort. There was no relevant medical or therapeutic history. The patient was a former smoker and consumed approximately 14 units ( 1 unit = approximately $200 \mathrm{~mL}$ ) of alcohol per week. An orthopantomograph showed no associated radiological abnormality. An incisional biopsy of the

${ }^{1}$ Guy's, King's and St Thomas' School of Medicine and Dentistry; '2 Oral and Maxillofacial Pathology Unit, Eastman Dental Institute, University College London; ${ }^{3}$ Maxillofacial Unit, University College London Hospitals NHS Trust, London, United Kingdom

Correspondence and reprints: Mr Adekunmi Fasanmade, 31 Sovereign Road, Barking, Essex IG11 OXQ, United Kingdom.

Telephone +44-208-596-9152, fax +44-208-984-9357, e-mail adekunmi.fasanmade@kcl.ac.uk, kunmi@fasanmade.freeserve.co.uk 


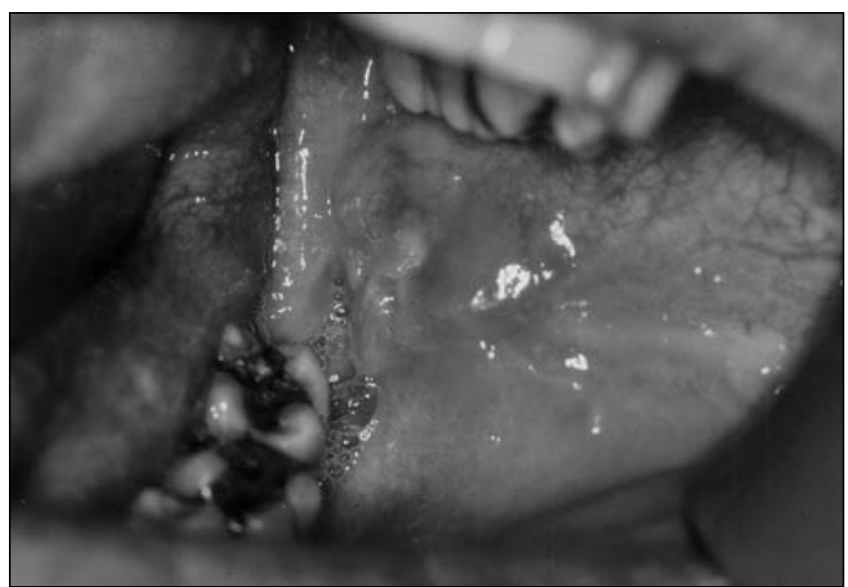

Figure 1) Swelling of left cheek mucosa adjacent to the molar teeth. Posterior to this, there is evidence of trauma from the maxillary teeth

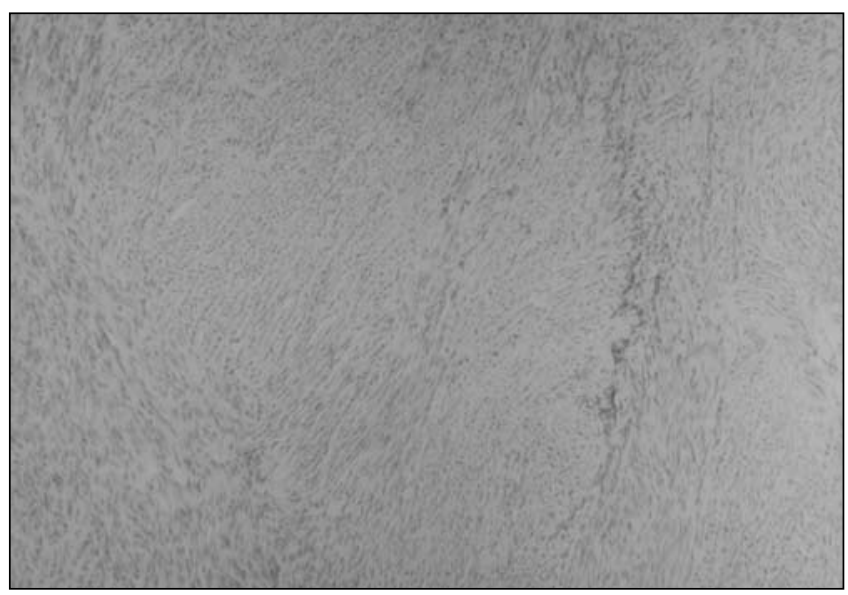

Figure 2) Photomicrograph showing leiomyosarcoma composed of interlacing bundles (fascicles) of spindle cells. (Hematoxylin and eosin stain, original magnification $\times 100$ )

mass was undertaken along with removal of the lower left third molar under general anesthesia. The subsequent histology was reported as an intraoral leiomyosarcoma, possibly metastatic. At this point the patient was referred to our unit for further management and was seen in the joint oncology clinic.

Further imaging was undertaken to exclude the possibility of a primary focus at a distant site; however, computed tomography of the chest, abdomen and pelvis failed to reveal any abnormality at these sites. Magnetic resonance imaging of the head and neck suggested no evidence of regional nodal metastatic disease. Therefore, a working diagnosis of primary intraoral leiomyosarcoma was made.

Subsequent management involved wide excision of the tumour in the left cheek, with a marginal resection of the adjacent mandible. The tumour resection included an incontinuity left supraomohyoid neck dissection. Intraoral reconstruction was performed with a fasciocutaneous radial forearm free flap.

A further surgical excision was required due to involved bone margins, and the initial reconstruction was removed. A segmental mandibulectomy from the left mental foramen

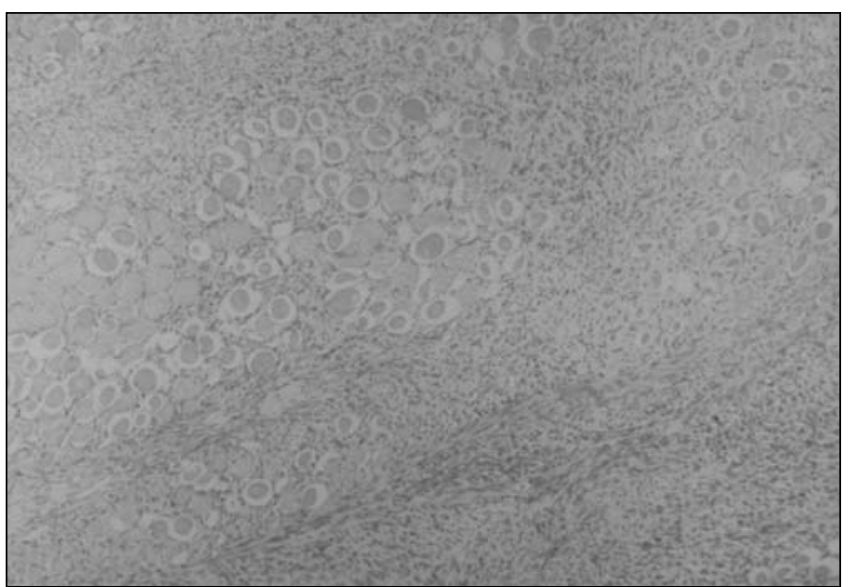

Figure 3) Leiomyosarcoma penetrating and destroying striated muscle. (Hematoxylin and eosin stain, original magnification $\times 100$ )

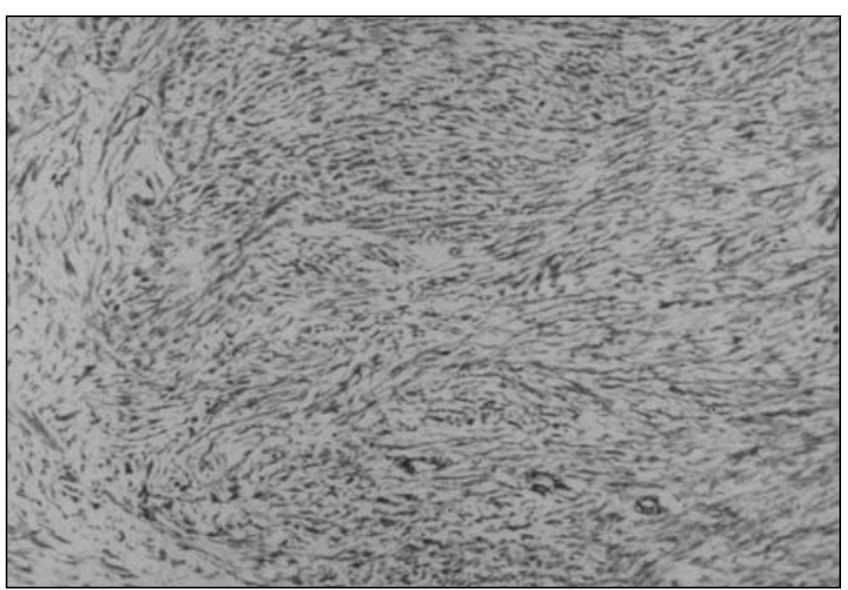

Figure 4) The neoplastic cells express smooth muscle actin. (Streptavidin-biotinylated immunoperoxidase stain, original magnification $\times 180)$

to the left angle was performed, and the resultant defect was reconstructed using a composite radial forearm free flap. After an uneventful recovery, the patient underwent a course of postoperative adjuvant radiotherapy; $60 \mathrm{~Gy}$ in 30 fractions was delivered to the tumour bed and 50 Gy was delivered to the left side of the neck. The patient remained free of disease 13 months after the operation.

\section{HISTOPATHOLOGY}

The mucosal resection showed intact parakeratinized stratified squamous epithelium overlying uninvolved lamina propria. However, the submucosa was extensively invaded by a spindle cell tumour composed of interlacing fascicles of cells (Figure 2) that had destroyed mucous salivary glands and striated muscle (Figure 3). The cells had undulating, blunt-ended nuclei of variable size that were hyperchromatic in places. Mitoses, some of abnormal morphology, were seen at a frequency of five per 10 high power fields. The tumour extended to a maximum depth of $1.1 \mathrm{~cm}$. Immunohistochemically, the neoplastic cells expressed smooth muscle actin (Figure 4), desmin and vimentin, but not $\mathrm{S} 100$ protein, cytokeratin or CD34, a 
phenotype consistent with leiomyosarcoma. Nineteen cervical lymph nodes were retrieved, but none contained metastatic tumour.

\section{DISCUSSION}

Primary intraoral leiomyosarcomas are rare and are thought to arise from smooth muscle elements in blood vessel walls or undifferentiated mesenchymal elements (14-16). Since Carmody et al's (17) initial report in 1944, there have been only 71 cases reported in the literature (2-13), excluding two cases of pharyngeal leiomyosarcoma $(18,19)$ and two cases that occurred in major salivary glands $(20,21)$. There have been only nine previously reported cases that occurred on the mucosal aspect of the cheek $(2,13)$. Intraoral leiomyosarcomas may present at any age, and have an overall male to female ratio of 2:1 (22). The sites of presentation are shown in Table 1. The most common site is the jaw. Presenting features include swelling, which may or may not be painful, and ulceration or discoloration of the mucosal surface. Thirty-nine per cent of patients with primary intraoral leiomyosarcoma complain of swelling at presentation and $31 \%$ complain of pain (13). Approximately 33\% of tumours are ulcerated (22), and tooth mobility may be an early sign of leiomyosarcoma of the jaw (3).

Surgical excision is the most appropriate curative treatment for primary leiomyosarcomas (4), and wide excision with a substantial margin of normal tissue is advocated. Although some regard prophylactic radical neck dissection as unnecessary (23), an ipsilateral selective neck dissection on the side of the tumour was carried out in this case for two reasons. First, it enabled histological evaluation of the cervical lymph nodes in the neck and accurate staging, a valuable procedure because oral leiomyosarcoma has been reported to undergo regional spread $(14,24-27)$ in $15 \%$ of cases (22), with distant metastasis in 39\%, an eventuality that is more likely with increasing tumour size (13). Furthermore, leiomyosarcomas at other anatomical sites, with a mitotic rate as high as five per 10 high power fields, as was the case with the present patient's lesion, are capable of metastasis (28). The possibility that this tumour was a secondary deposit was excluded by radiological means, but leiomyosarcomas of the gastrointestinal tract, female genitourinary tract and retroperitoneal origin can metastasize to

\section{REFERENCES}

1. Enzinger FM, Weiss SW. Soft Tissue Tumors, 3rd edn. St Louis: CV Mosby Co, 1995.

2. Mesquita RA, Migliari DA, Machado de Souza SO, Alves MR. Leiomyosarcoma of the buccal mucosa. J Oral Maxillofac Surg 1998;56:504-7.

3. Carter LC, Aguire A, Boyd B, DeLacure MD. Leiomyosarcoma of the mandible in 7 year old girl: Report of a case and review of the literature. Oral Surg Oral Med Oral Path Oral Radiol Endod 1999;87:477-84.

4. Lo Muzio L, Favia G, Mignogna M, Paittelli A, Maiorano E. Primary intraoral leiomyosarcoma of the tongue: An immunohistochemical study and review of the literature. Oral Oncology 2000;36:519-24.

5. Goldschmidt P, Goldschmidt J, Lieblich S, Eisenberg E. Leiomyosarcoma presenting as a mandibular gingival swelling: A case report. J Periodontol 1999;70:84-9.

\begin{tabular}{|c|c|}
\hline Site & Number of cases (\%) \\
\hline Mandible & $18(25.0)$ \\
\hline Maxilla & $18(25.0)$ \\
\hline Tongue & $10(13.9)$ \\
\hline Cheek & $10(13.9)$ \\
\hline Hard and/or soft palate & $9(12.5)$ \\
\hline Floor of mouth & $4(5.5)$ \\
\hline Lip & $3(4.2)$ \\
\hline Total & 72 \\
\hline
\end{tabular}

the oral cavity (29). Second, the neck dissection provided access to the vessels in the neck to facilitate optimal free tissue transfer reconstruction. These factors, coupled with the low morbidity associated with contemporary selective neck dissection, justified the additional surgery.

The value of postoperative radiotherapy is disputed. Chang et al (30) made a case for the use of radiotherapy as an adjunct to surgery for residual microscopic disease. This approach is supported by some $(22,25,30)$, but not by others $(27,31,32)$. There appears to be no role for chemotherapy in primary or adjuvant treatment, but it may be indicated for palliation of disseminated disease $(22,27,30,32)$. The rate of recurrence has been reported at $35 \%$ to $50 \%(22,33)$, with a five-year disease-free survival rate of $23 \%$ and a fiveyear mortality rate of $69 \%$.

\section{CONCLUSION}

Intraoral leiomyosarcoma is a rare tumour with a poor prognosis. Wide local excision is the most appropriate primary treatment with, we believe, selective neck dissection of the ipsilateral neck. Adjuvant radiotherapy is indicated in cases where there is residual disease.
6. Picard A, Michalak S, Bonin B, Fassio E, Goga D. Osseous leiomyosarcoma of the mandible: Case report and review of the literature. Rev Stomatol Chir Maxillofac 2000;101:142-6.

7. Ayad W, Dieckmann J, Freitag P, Wierich W. Leiomyosarcoma of the mandibular canal: Possible differential diagnosis of cystic processes of the mandible. Mund Kiefer Gesichtschir 1998;2:42-3.

8. Das DK, Grover RK, Anand VJ, et al. Oral leiomyosarcoma in childhood: Report of a case with fine needle aspiration cytology. Acta Cytol 1999;43:1150-4.

9. Savastano G, Palombini L, Muscariello V, Erra S. Leiomyosarcoma of the maxilla: a case report. J Oral Maxillofac Surg 1998;56:1101-3.

10. Moussaoui O, Menard P. Leiomyosarcoma of the gingiva: Apropos of a case. Review of the literature. Rev Stomatol Chir Maxillofac 1998;99:132-7.

11. Dios PD, Teijeiro JC, Anguira FB, Scully C, Garcia EV, Garcia- 
Garcia A. Synchronous oral leiomyosarcoma and squamous cell carcinoma. Oral Surg Oral Med Oral Pathol Oral Radiol Endod 2001;91:70-5.

12. Sumida T, Hamakawa H, Otsuka K, Tanioka H. Leiomyosarcoma of the maxillary sinus with cervical lymph node metastases. J Oral Maxillofac Surg 2001;59:568-70.

13. Wertheimer-Hatch L, Hatch G III, Hatch K, et al. Tumours of the oral cavity and pharynx. World J Surg 2000;24:395-400.

14. Izumi K, Maeda T, Cheng J, Saku T. Primary leiomyosarcoma of the maxilla with regional lymph node metastases: report of case and review of the literature. Oral Surg Oral Med Oral Pathol Oral Radiol Endod 1995;80:310-9.

15. Kratochvil FJ 3rd, MacGregor SD, Budnick SD, Hewan-Lowe K, Allsup HW. Leiomyosarcoma of the maxilla: Report of a case and review of the literature. Oral Surg Oral Med Oral Pathol 1982;54:647-55.

16. Martin-Hirsch OP, Habashi S, Bendow EW, Farrington WT. Post-irradiation leiomyosarcoma of the maxilla. J Laryngol Otol 1991;105:1068-71.

17. Carmody TE, Janney JM, Husesman HAL. Leiomyosarcoma of mandible: Report of case. J Am Dent Assoc 1944;31:1110-3.

18. Mankodi RC, Shah SS, Kanvinde MS, Joshi JS. Pharyngeal leiomyosarcoma. J Laryngol Otol 1970;84:327-30.

19. Glover GW, Park WW. Pharyngeal leiomyosarcoma. J Laryngol Otol 1971;885:1031-8.

20. Sandhyamani S, Mahapata AK, Kapur BM. Leiomyosarcoma of the parotid gland. Aust NZ J Surg 1983;53:179-81.

21. Kang J, Levinson JA, Hitti IF. Leiomyosarcoma of parotid gland: A case report and review of the literature. Head Neck 1999;21:168-71.

22. Schenberg ME, Slootweg PJ, Koole R. Leiomyosarcomas of the oral cavity. Report of four cases and a review of the literature. J Cranio Max Fac Surg 1993;21:342-7.

23. Haedicke G, Kaban L. Smooth muscle tumours of the oral cavity. Plast Reconstr Surg 1988;81:264-9.

24. Dry SM, Jorgensen JL, Fletcher CDM. Leiomyosarcomas of the oral cavity: an unusual topographic subset easily mistaken for non- mesenchymal tumours. Histopathology 2000;36:210-20.

25. Poon CK, Kwan PC, Yin NT, Chao SY. Leiomyosarcoma of gingivae: Report of a case and review of the literature: J Oral Max Surg 1987;45:888-92.

26. Freedman P, Jones A, Kerpel S. Epitheloid leiomyosarcoma of the oral cavity. J Oral Maxillofac Surg 1993;51:928-32.

27. Fu YS, Perzin KH. Non-epithelial tumours of the nasal cavity, paranasal sinuses and nasopharynx: A clinicopathologic study, IV: Smooth muscle tumours. Cancer 1975;35:1300-8.

28. Shmookler BM, Dauer DH. Retroperitoneal leiomyosarcoma: A clinicopathological analysis of 36 cases. Am J Surg Pathol 1983;7:269-80.

29. Allen CM, Neville B, Damm DD, Marsh W. Leiomyosarcoma metastatic to the oral region. Report of three cases. Oral Surg Oral Med Oral Pathol 1993;76:752-6.

30. Chang AE, Rosenberg SA, Glatstein EJ, Antman KH. Sarcomas of the soft tissues. In: De Vita VT Jr, Hellman S, Rosenberg SA. Cancer. Principles and Practice of Oncology, 3rd edn. Philadelphia: JB Lippincott, 1989:1371-3.

31. Fields JP, Helwig EB. Leiomyosarcoma of the skin and subcutaneous tissue. Cancer 1981;47:156-69.

32. Wile AG, Evans HL, Romsdahl MM. Leiomyosarcoma of soft tissue: A clinicopathologic study. Cancer 1981;48:1022-32.

33. Kissane J. Andreson's Pathology, 8th edn. St Louis: Mosby, 1985. 